\title{
Identifying treatment-resistant PTSD
}

Sci.Transl. Med. https://doi.org/10.1126/scitransImed.aal3236

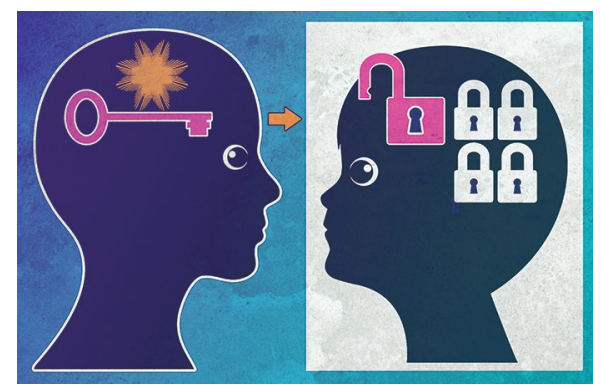

Credit: Sandema / Alamy Stock Photo

Post-traumatic stress disorder (PTSD) is a psychiatric disorder that is commonly treated by psychotherapy. However, not all patients respond to this treatment.

Amit Etkin, of Stanford University, and colleagues measured the dynamics of the brain at rest in a group of patients with PTSD and found that those who had trouble remembering a list of words also showed a different pattern of brain activation within the ventral attention network. These same patients also tended not to respond to psychotherapy, suggesting that the combination of these behavioural and neural symptoms could be a 'signature' of non-responsive PTSD patients. This seems to be true: the researchers were able to use this signature to predict treatment response with $90 \%$ accuracy across a range of PTSD patients. Finally, Etkin and colleagues used non-invasive stimulation to identify a region of the brain that was able to change the function of the network they identified.

Taken together, this research identifies a neural and behavioural phenotype of treatment-resistant PTSD and indicates a potential target for non-invasive brain stimulation that may be able to treat those PTSD patients who do not respond to psychotherapy.

\section{Mary Elizabeth Sutherland}

Published online: 16 May 2019

https://doi.org/10.1038/s41562-019-0627-1 